\title{
Analysis of nifH DNA and RNA reveals a disproportionate contribution to nitrogenase activities by rare plankton- associated diazotrophs
}

Qing-Song Yang ${ }^{1,3}$, Jun-De Dong ${ }^{1,2}$, Manzoor Ahmad ${ }^{1,3}$, Juan Ling ${ }^{1}$, Wei-Guo Zhou ${ }^{1,3}$, Ye-Hui Tan ${ }^{1}$, Yuan-Zhou Zhang ${ }^{4}$, Dan-Dan Shen ${ }^{5^{*}}$ (D) and Yan-Ying Zhang ${ }^{1,2^{*}}$

\begin{abstract}
Background: Holobionts comprising nitrogen-fixing diazotrophs and phytoplankton or zooplankton are ubiquitous in the pelagic sea. However, neither the community structure of plankton-associated diazotrophs (PADs) nor their nitrogenase transcriptional activity are well-understood. In this study, we used nifH gene Illumina sequencing and quantitative PCR to characterize the community composition and nifH expression profile of PADs with $>100 \mu \mathrm{m}$ size fraction in the euphotic zone of the northern South China Sea.

Results: The results of DNA- and RNA-derived nifH gene revealed a higher alpha-diversity in the active than in the total community. Moreover, the compositional resemblance among different sites was less for active than for total communities of PADs. We characterized the 20 most abundant OTUs by ranking the sum of sequence reads across 9 sampling stations for individual OTUs in both nifH DNA and RNA libraries, and then assessed their phylogenetic relatedness. Eight of the 20 abundant OTUs were phylogenetically affiliated with Trichodesmium and occurred in approximately equal proportion in both the DNA and RNA libraries. The analysis of nifH gene expression level showed uneven attribute of the abundance and nitrogenase activities by the remaining 12 OTUs. Taxa belonging to cluster III and Betaproteobacteria were present at moderate abundance but exhibited negligible nitrogenase transcription activity. Whereas, the abundances of Richelia, Deltaproteobacteria and Gammaproteobacteria were low but the contribution of these groups to nitrogenase transcription was disproportionately high.

Conclusions: The substantial variation in community structure among active dizatrophic fractions compared to the total communities suggests that the former are better indicators of biological response to environmental changes. Altogether, our study highlights the importance of rare PADs groups in nitrogen fixation in plankton holobionts, evidenced by their high level of nitrogenase transcription.
\end{abstract}

Keywords: Symbiosis, Nitrogen fixation, Presence-absence, Transcriptional activity, Dormancy, South China Sea

\footnotetext{
*Correspondence: dand.shen@gmail.com; zyy@scsio.ac.cn

${ }^{5}$ Section of Biological Oceanography, Leibniz Institute for Baltic Sea Research,

18119 Warnemünde, Germany

${ }^{1}$ CAS Key Laboratory of Tropical Marine Bio-resources and Ecology,

Guangdong Provincial Key Laboratory of Applied Marine Biology, South

China Sea Institute of Oceanology, Chinese Academy of Sciences,

Guangzhou 510301, China

Full list of author information is available at the end of the article
}

(c) The Author(s). 2019 Open Access This article is distributed under the terms of the Creative Commons Attribution 4.0 International License (http://creativecommons.org/licenses/by/4.0/), which permits unrestricted use, distribution, and reproduction in any medium, provided you give appropriate credit to the original author(s) and the source, provide a link to the Creative Commons license, and indicate if changes were made. The Creative Commons Public Domain Dedication waiver (http://creativecommons.org/publicdomain/zero/1.0/) applies to the data made available in this article, unless otherwise stated. 


\section{Background}

Nitrogen fixation by marine diazotrophs compensates for the loss of nitrogen through sinking and denitrification [1] and supports primary productivity in marine ecosystems [2-4]. The dominant $\mathrm{N}_{2}$ fixers in the world's oceans are diazotrophic cyanobacteria, which are composed of three major groups: filamentous non-heterocystforming cyanobacteria, heterocystous cyanobacteria, and unicellular cyanobacteria [5]. Trichodesmium, a genus of filamentous non-heterocystous cyanobacteria, is thought to be the major contributor to marine nitrogen fixation globally [6-8]. As members of heterocystous cyanobacteria, the Richelia co-exist with diatoms and are commonly present in the open oceans $[9,10]$. A recent investigation of a unicellular cyanobacteria group (UCYNA) pointed out the need to re-evaluate the underestimated contribution of unicellular cyanobacteria to marine nitrogen fixation [11]. In recent years, the nifH gene, a gene encoding a subunit of nitrogenase enzyme, has been frequently used to explore the diversity of diazotroph [12]. In addition to autotrophic diazotrophic cyanobacteria, the nifH gene maker have identified highly diversified noncyanobacterial heterotrophic diazotrophs in a wide oligotrophic aquatic environments $[12,13]$.

Holobionts comprising nitrogen-fixing diazotrophs and phytoplankton or zooplankton are ubiquitous in the pelagic sea $[14,15]$. Trichodesmium in the holobionts form large colonies (millimeter size), and provide a micro-niche for diverse assemblages of microorganisms including autotrophic and heterotrophic diazotrophs. Despite that Trichodesmium is non-symbiotic diazotrophs, its colony-forming lifestyle sustains the growth of diverse symbiotic diazotrophic species [16, 17]. Various symbiotic strategies between plankton-associated diazotrophs (PADs) and their hosts facilitate marine biologic nitrogen fixation in the holobionts. Symbionts of diazotrophic cyanobacteria are exemplified by the genus Richelia, displaying symbiotic association with eukaryotic algae Rhizosolenia and other diatoms [9, 18-21]. The symbiotic strategies of autotrophic cyanobacterial diazotrophs, including symbiotic unicellular cyanobacteria [22], have been extensively documented. Nonetheless, the symbiotic phenomenon is not unique to autotrophic cyanobacterial diazotrophs and also exists in heterotrophic nitrogen-fixing bacteria [23-25]. This was demonstrated in a ${ }^{15} \mathrm{~N}$-incorporation experiment that showed $\mathrm{N}_{2}$ fixation in the copepod gut by heterotrophic symbiotic diazotrophs, and the vital role of that symbiosis in marine nitrogen cycles [26].

The diversity and distribution of PADs have been extensively studied by means of DNA-derived nifH clone libraries [13, 24-26] and high-throughput sequencing [27]. However, due to the high degree of dormancy of environmental microbes $[28,29]$, the contribution of nitrogen fixation and community dynamics may be incorrectly estimated if based solely on data obtained from nifH DNA analysis [11, 30]. Instead, the use of both DNA - and RNA-derived assessments of microbial communities allows the additional identification of the rare but metabolically active microbes present in natural environments [31-33]. In the case of PADs, despite their key role in converting nitrogen in marine ecosystems, their nitrogenase transcription activity is poorly understood. Moreover, differences in the abundance and activity of different PADs groups have yet to be investigated.

Non-cyanobacteria predominated the bulk diazotrophic communities of the northern South China Sea in previous field studies [34, 35] whereas the community structure of the PADs remains largely unexplored. Thus, in the present study, we extended previous work and used high-throughput nifH gene amplicon sequencing to characterize the total and active communities of PADs inhabiting the northern South China Sea. In addition, by analyzing nifH gene expression, we were able to identify differences in nitrogenase transcription activity by the different phylogenetic groups of PADs depending on their symbiotic strategies.

\section{Results}

\section{Alpha- and beta-diversity}

We retrieved a total of 762,968 valid nifH sequences from the 18 DNA- and RNA-derived libraries. After quality filtering, the valid sequences $(310-380 \mathrm{bp})$ were clustered into 731 OTUs at the $94 \%$ sequence similarity level. From a total of 731 OTUs, 153 OTUs were present in all nine samples of the DNA library, 109 OTUs in all nine samples of the RNA library, and 104 OTUs in both the DNA and the RNA libraries. For simplicity, we refer to nifH DNA-sequence composition as 'total community', while nifH RNA-sequence composition as 'active community' throughout the manuscript.

To evaluate the diversity of the diazotrophic assemblages in the total and active PADs communities, the Shannon index, Simpson index, Pielou evenness, and Chao 1 index, as alpha-diversity parameters, were determined in each sample based on the number of nifH-sequence-derived OTUs. Generally, each alpha-diversity parameter was significantly higher in the active than in the total communities (ANOVA, $P<0.05$; Fig. 1), despite some variation in each diversity index among the stations (Additional file 1: Table S2).

The beta-diversity of the total and active PADs communities was investigated as well, with the differences in between-group community composition visualized in a NMDS plot (Fig. 2a). The total PADs communities were taxonomically distinct according to their sampling origin (average Bray-Curtis distance, $0.06 \pm 0.02$ ). However, regardless of their origin, the total PADs communities 

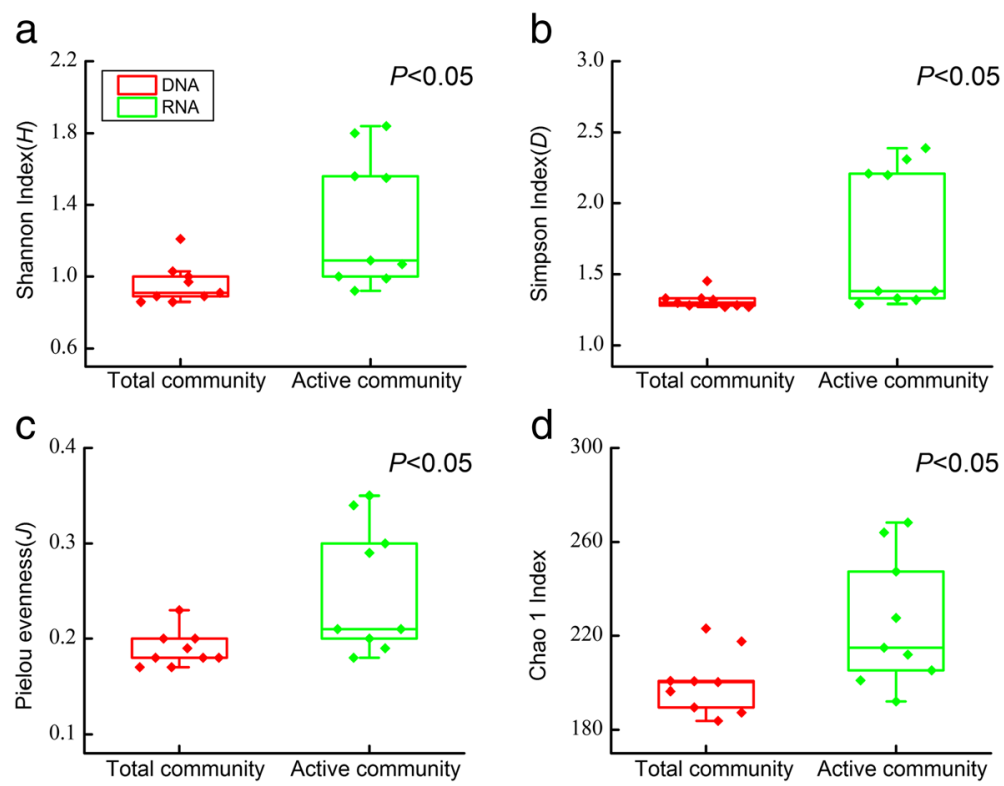

Fig. 1 Alpha-diversity of the total and active plankton-associated diazotrophs (PADs) communities. Shannon index (a), Simpson index (b), Pielou evenness (c) and Chao 1 index (d) of the total and active PADs community based on nifH-derived DNA and RNA libraries. The dots indicate the diversity index value of each sample

clustered together in the NMDS scatter plot whereas the active PADs communities were more dispersed (average Bray-Curtis distance, $0.22 \pm 0.11$; Fig. 2a). To better understand the mean between-community differences in dependence of presence-absence or metabolic activity, a beta-dispersion analysis was performed to quantify the between-group variation within the total and active PADs communities. Between-community variation was significantly lower in the total PADs communities than in the active fractions (ANOVA, $P<0.001$; Fig. 2b), suggesting that the differences in the diazotrophic communities across all stations with respect to the presenceabsence of the nifH gene were smaller than the differences in nifH expression.

\section{The composition and environmental relationships of diazotrophs}

To visualize the phylogenetic diversity of the diazotrophs, a phylogenetic tree was constructed using the nifH sequences of the 20 most abundant OTUs (comprising $90.3 \%$ of the total nifH DNA and RNA sequences) and reference sequences (Fig. 3). The retrieved nifH sequences belonged to a wide range of diazotrophic groups, including Trichodesmium, heterocystous cyanobacteria, unicellular cyanobacteria, Gammaproteobacteria, Deltaproteobacteria, Betaproteobacteria and diazotrophs of cluster III (Fig. 3).

Trichodesmium predominated in both the total and the active fractions of the PADs communities across all stations, representing, on average, $98 \%$ and $87 \%$ of the
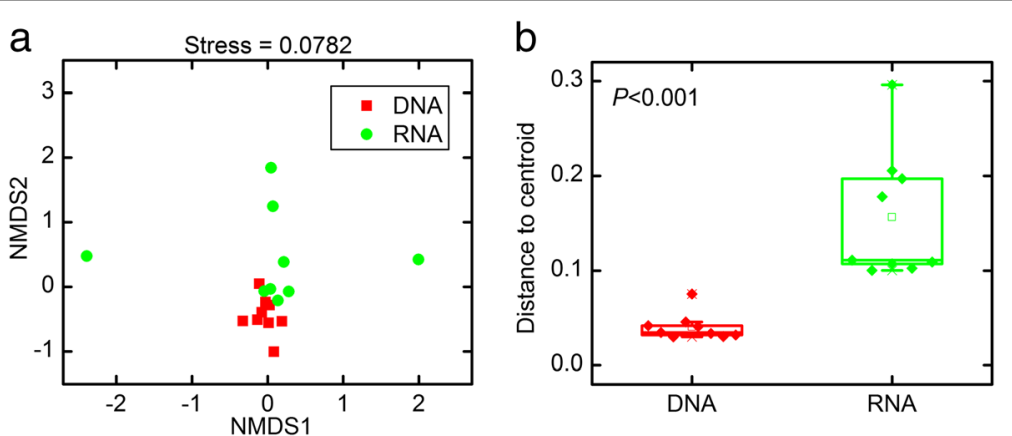

Fig. 2 Beta-diversity of the total and active PADs communities. a Similarity among total and active PADs communities as determined by non-metric multidimensional scaling ordination. $\mathbf{b}$ Beta-dispersion illustrating the difference in the between-community variation of the nifH DNA and nifH RNA libraries. The significance of the between-community variation within total and active PADs was statistically tested by ANOVA 


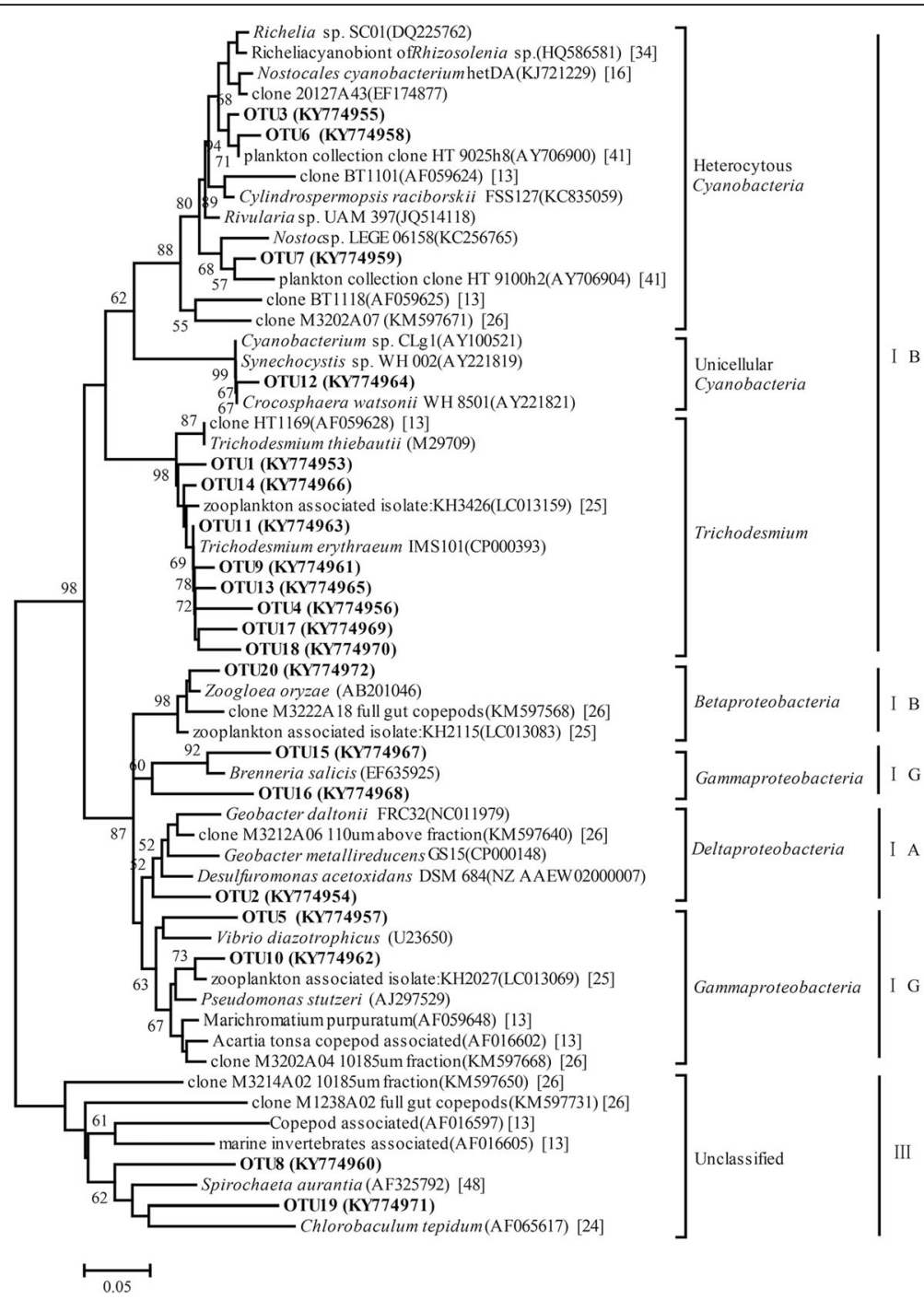

Fig. 3 Unrooted neighbor-joining phylogenetic tree based on the nifH amino acid sequences of the 20 most abundant OTUs and reference sequences. The bootstrap values (> 50\%) of relevant nodes are shown based on 1000 replicates. Sequences from this study are shown in bold. Scale bars: $5 \%$ of the estimated sequence divergence. The number in square brackets refers to the studies in which the reference sequences were previously reported

nifH DNA and nifH RNA sequences, respectively (Fig. 4). Eight of the 20 most abundant OTUs were affiliated with Trichodesmium, thus indicating a divergent phylogenesis of the Trichodesmium nitrogenase gene (Fig. 3). Specifically, the relative abundance of Trichodesmium was relatively stable at all stations, ranging from 95.5 to $99.7 \%$ within the individual DNA libraries (Fig. 4). However, the variation in the relative abundance of this genus was more pronounced in the RNA libraries, ranging from $65.7 \%$ at station $\mathrm{F}$ to $99.4 \%$ at station B (Fig. 4).

Some diazotrophs were enriched in the RNA libraries compared to their relative abundance in the DNA libraries, while for others the opposite was the case (Fig. 4). For example, Richelia-like heterocystous cyanobacteria were absent or of lower abundance $(0.2 \%)$ in the total
PADs communities but reached moderate abundances in eight of the nine stations (Fig. 4). Plankton-associated Deltaproteobacteria were over-represented in the active PADs community of station F, and a similar pattern was observed for Gammaproteobacteria at station A (Fig. 4). Unicellular cyanobacteria, whose nifH sequences clustered together with those of Crocosphaera watsonii WH 8501 (Fig. 3), accounted for only $0.01 \%$ of the nifH DNA sequences, but their contribution to the nifH RNA sequences was higher $(0.5 \%)$. Conversely, taxa affiliated with cluster III and Betaproteobacteria accounted for an average of $1.11 \%$ and $0.33 \%$, respectively, of the abundance based on the DNA libraries across stations, but their abundances were negligible in the RNA libraries (Fig. 4). 


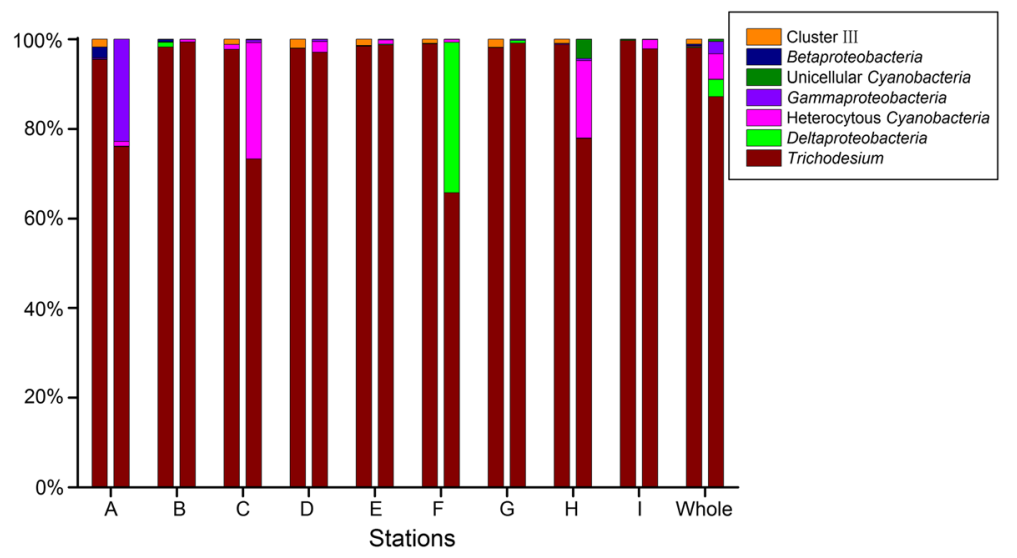

Fig. 4 Composition of nifH taxa based on DNA- and RNA-derived libraries. For all stations (A-I), the left bars represent the DNA-derived libraries and the right bars the RNA-derived libraries; "whole" refers to the average relative abundance of all samples

We then explored the relationship between community composition and the corresponding environmental variables. Since the physical and chemical parameters of the water column vary with water depth and sampling site (see Additional file 1: Table S3 and Figure S1), separate RDA analyses were performed for surface and averaged (across depths) environmental parameters. Total and active PADs communities significantly correlated with sea surface $\mathrm{pH}$, water column average $\mathrm{pH}$, concentrations of average nitrate plus nitrite, and the average ammonium concentration (Additional file 1: Table S4). Several environmental factors significantly influenced the abundance and activity of Trichodesmium. Both total and active Trichodesmium highly correlated with sea surface $\mathrm{pH}(P=0.019)$, water column average $\mathrm{pH}(P=$ $0.021)$, and marginally correlated with average nitrate plus nitrite concentrations $(P=0.100)$ (Additional file 1: Figure S3 and Table S4). However, there was no significant correlation between total and/or active heterocystous cyanobacteria and any of the environmental variables (Additional file 1: Figure S3).

\section{Proportions of abundant OTUs}

To assess whether the 20 most abundant OTUs accounted for a disproportionate amount of nifH gene activity, we compared the relative abundances (frequencies) of each OTU in the DNA and RNA libraries (Fig. 5). The relative abundance of OTU1 was $>50 \%$ in both libraries in all samples, while the remaining 19 OTUs were less abundant (Fig. 5). The frequencies of all eight OTUs affiliated with Trichodesmium were approximately equal in the DNA and RNA libraries, with disproportionate frequencies determined for the remaining 12 OTUs. For example, OTUs affiliated with members of heterocystous cyanobacteria, unicellular cyanobacteria, Gammaproteobacteria, and Deltaproteobacteria were of relatively high but varying frequencies in the nifH RNA libraries (Fig. 5) whereas the OTUs of members of the Betaproteobacteria and diazotrophs of cluster III were of negligible frequency in the RNA but not the DNA libraries (Fig. 5).

\section{$\mathrm{NifH}$ gene expression level}

The nifH gene expression level of the bulk PADs communities ranged from 0.0042 to 0.52 , with an average nifH RNA/DNA ratio of 0.17 (Fig. 6). To further quantify nifH gene expression by the different PADs groups, we calculated the nifH RNA/DNA ratio of the main groups by combining the bulk community nifH RNA/DNA ratio with the frequencies of the dominant groups. Heterocystous cyanobacteria were the most active group, based on nifH RNA/DNA ratios ranging from 0.39 to 13.82 (average nifH RNA/ DNA ratio 3.51). Trichodesmium predominated in the total and active PADs communities (Fig. 4), but nifH gene expression by this genus (average nifH RNA/ DNA ratio 0.15) was somewhat lower than that of the bulk community (0.17). Unicellular cyanobacteria, Deltaproteobacteria and Gammaproteobacteria were present at low abundances (Fig. 4) but exhibited highlevel nifH expression (Fig. 6), whereas nifH mRNA expression by diazotrophs of cluster III and Betaproteobacteria was nearly undetectable. Due to high between-sample variations, which might be caused by environmental differences, there was no statistically significant difference in the nifH RNA/DNA ratio of the analyzed PADs groups.

\section{Discussion}

The aim of this study was to elucidate the community structure and nifH mRNA expression of diazotrophs associated with plankton with a particle size $>100 \mu \mathrm{m}$ in northern South China Sea. Our results showed that the active PADs communities were taxonomically distinct from the total communities. Trichodesmium 


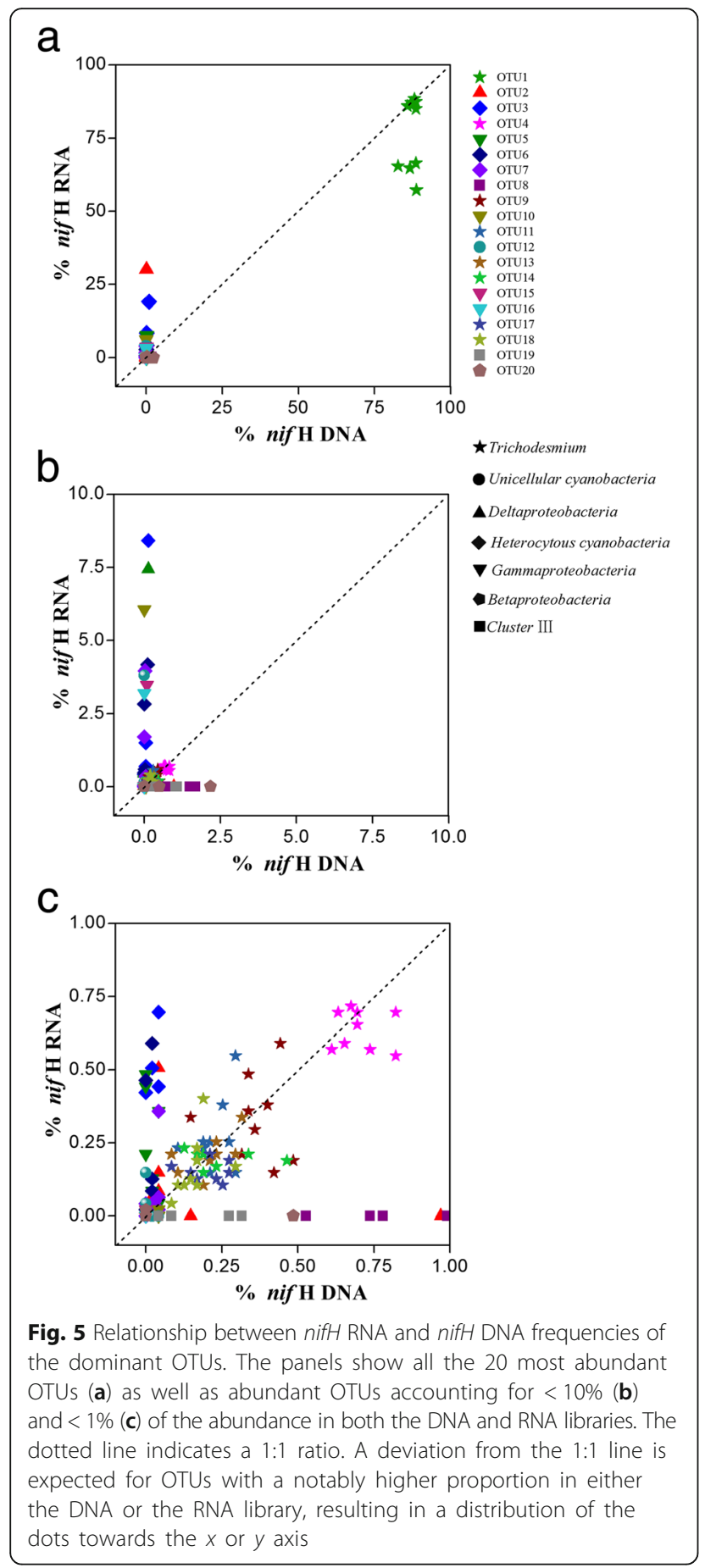

predominated among the PADs of the euphotic zone, with approximately equal abundances in the DNA and RNA libraries. Differences in the nifH gene expression levels of the different phylogenetic groups of diazotrophs may be related to the life forms and symbiotic strategies of these organisms.

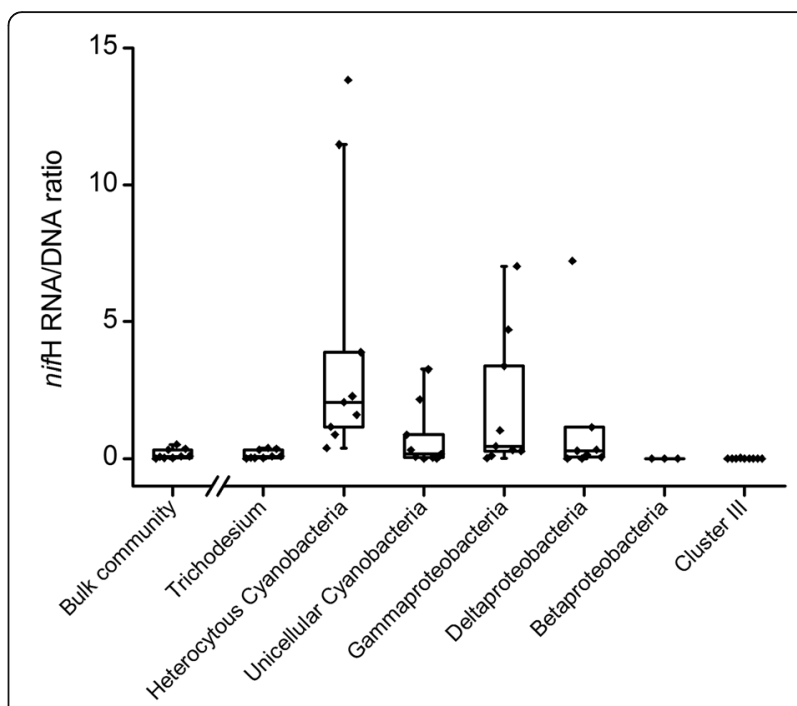

Fig. 6 The nifH mRNA expression level of the main groups. The expression ratio is based on the quantitative PCR results of each sample combined with the average taxonomic frequencies in the nifH DNA and RNA libraries. The dots represent the nifH RNADDNA ratio of each sample. For some samples, the ratio is not provided because no sequence was found in the DNA libraries

\section{Active communities are more diverse and divergent than total communities}

In determinations of the microbial communities in a particular environment, higher community diversity in DNA- than in RNA-derived libraries is typical and has been demonstrated in several $16 \mathrm{~S}$ rRNA-based studies $[33,36-39]$. Here we directly tracked nifH-defined communities, because nifH gene may provide better insight into the diversity and composition of the communities that are capable of nitrogen fixation in an environment than those extrapolated from 16S rRNA data. However, our nifH sequence analysis revealed a higher alphadiversity in the active (based on RNA) than in the total (based on DNA) communities of PADs (Fig. 1). The evenness of the total PADs communities was also lower than that of the metabolically active communities, as indicated by the very small number of highly dominant taxa. The nifH gene-based OTU abundances from the DNA analysis do not always predict which diazotrophic OTU is actively expressing nifH assessed in the RNA analysis. The former one is presumably considered a proxy for the dominant diazotrophs in a given sample, whereas the latter offers a representation of metabolically active diazotrophs with regard to nitrogen fixation processes. A high alpha diversity in a given community could be a result of high evenness. As such, a higher evenness obtained from nifH RNA-based OTU analysis accounts for closer number among individuals that were actively expressing nifH, relative to the communities comprising a few highly dominant diazotrophs detected 
in nifH DNA based approach. This is supported by the prevalence of Trichodesium in all DNA-derived communities and the decline in its abundance in the RNAderived communities, whereas some taxa that were rare in the total communities were of moderate abundance in the active communities (Fig. 4). Thus, although the lowabundance groups represented a small proportion of the total PADs community biomass, they contributed a disproportionately high amount of the activity, presumably due to active transcription of nitrogenase mRNA under suitable growth conditions.

Previous studies have confirmed the dissimilarities between total and active diazotrophic communities [40, 41], but the variability within communities of total and active diazotrophshas not been quantitatively investigated. Given that changes occur faster in RNA than in DNA [42], we hypothesized a more pronounced variability in the active diazotrophic communities (RNA) across stations than in the total communities (DNA). Indeed, variations in the community structures of PADs among sampling sites were observed and were independent of the presence or activity of the cells. However, in accordance with our hypothesis, this variation was significantly higher in the active fraction of the diazotrophic communities than in the total communities (Fig. 2b). Moreover, the differences between the active communities at different sites were mainly caused by the replacement of taxa, rather than changes in the abundance of common taxa (Fig. 4), suggesting that different selective pressures determine the turnover in membership of metabolically active diazotrophs in the studied ecosystems. Accordingly, active diazotrophic assemblages may better reflect the response of PADs to environmental alterations.

\section{A varying level of metabolic activity among rare taxa}

Given that some taxa tend be to conditionally rare [43], investigations of membership turnover in rare but active populations of natural communities may shed light on microbial diversity and succession. In our study, rare but active PADs groups included heterocystous cyanobacteria, unicellular cyanobacteria, Deltaproteobacteria and Gammaproteobacteria (Figs. 4 and 6). Members of the heterocystous cyanobacterial genus Richelia were the most transcriptionally active group. The heterocystous cyanobacteria Richelia has been extensively reported as a diatom symbiote, including the investigations in the South China Sea [34, 35], and was identified to actively transfer nitrogen to their diatom hosts [15]. The association of diazotrophic unicellular cyanobacteria with phytoplankton has been the subject of recent studies $[11,27,44]$, including a report describing a high nitrogen fixation rate and rapid nitrogen transfer from symbiotic unicellular cyanobacteria to their hosts, evidenced by $\mathrm{N}$-isotope-based nano-SIMS technology [11]. The highly active transcription of nitrogenase mRNA by intracellular symbiotic Richelia and unicellular cyanobacteria detected in our study is in agreement with previous studies reporting high nitrogen fixation rates by those diazotrophs $[11,15]$. Intracellular symbiotic strategies and nutrient exchange mechanisms may facilitate a high efficiency of nitrogen fixation by Richelia as well as unicellular cyanobacteria.

High nitrogenase mRNA transcription level was also detected in Deltaproteobacteria and Gammaproteobacteria, previously reported to be dominant diazotrophic groups [35, 45]. In our study, although Deltaproteobacteria was present at low abundance, its level of nifH mRNA transcription activity was high. This group was detected in copepods in previous studies $[24,26]$ whereas in the case of diazotrophic Gammaproteobacteria little is known about its symbiotic relationships. Fluorescence in situ hybridization studies of diazotrophic Gammaproteobacteria may lead to the identification of its host and thus provide insights into the ecological importance of this PADs group.

\section{The inactive diazotrophic groups}

Nitrogenase is a multi-component enzyme with several different forms, although the nifH gene encodes a highly conserved subunit [30]. However, the nifH gene also shares a similarity with nifH-like genes in non-diazotrophic organisms, such that many nifH sequences retrieved from environmental clones are in fact pseudogenes [46, 47]. In this study, nifH sequences belonging to cluster III were the second most abundant group in the nifH DNA libraries, but few transcripts were detected in the nifH RNA libraries for all stations (Figs. 4 and 5). Considering that the cluster III nifH sequences obtained in this study were not transcribed, whether they were pseudogenes or indeed belonged to inactive groups was unclear. The reference sequences that clustered closely with the sequences of cluster III (Fig. 3) originated from zooplankton and the termite gut $[24,48]$. In addition, the nitrogenase activity of PADs was shown to be much higher in starved copepods than in fullgut copepods [26]. It was therefore hypothesized that, the presence of sufficient bio-available nitrogen in the zooplankton gut down-regulates nitrogenase gene expression [26]. Similarly, the cluster III diazotrophs found in our study might be those inactive members associated with zooplankton, which would imply that zooplanktonassociated heterotrophic diazotrophs are suppliers of extra nitrogen for their hosts, especially under conditions of starvation.

\section{Trichodesmium dominate the PADs}

The results of microscopy-based cell counting showed a relatively lower Trichodesmium abundance $\left(1.29 \times 10^{3}\right.$ $8.22 \times 10^{3}$ trichomes $\mathrm{m}^{-2}$ in the euphotic waters, 
Additional file 1: Figure S2) in the South China Sea than previously reported [34, 35, 49]. The differences may have been due to the use of different sampling methods, as the net-tow $(100-\mu \mathrm{m}$ mesh) collection of plankton in our study would have excluded free-living or smaller aggregates of Trichodesmium cells, both of which are captured in previous studies using smaller pore-size filters $(0.2-, 10-$ or $20-\mu \mathrm{m})[34,35,49]$. Nevertheless, the sampling method used in our study was chosen to ensure collection of the PADs fraction while excluding freeliving diazotrophs, as that different patterns for PADs and whole diazotrophic communities were expected.

Trichodesmium is one of the dominant diazotrophs in tropical and subtropical oceans $[5,6,50]$. In the South China Sea, heterotrophic Proteobacteria was shown to dominate the diazotrophic communities [34, 35]. However, consistent with the results of Farnelid and colleagues, who reported the predominance and enrichment of cyanobacteria, including Trichodesmium, in diazotrophic communities associated with sinking particles [27], we found that Trichodesmium accounted for nearly all of the PADs $(\sim 98 \%)$ in our samples. It seems that autotrophic cyanobacterial diazotrophs such as Trichodesmium tend to dominate in large particle-size fraction of the diazotrophic community inhabiting the euphotic-zone, while heterotrophic diazotrophs tend to be free-living. Alternatively, the disproportional enrichment of Trichodesmium in the $>100 \mu \mathrm{m}$ size fraction could be resulted from colonization of their cells. Thus, our collection method revealed a difference in the community structure of bulk diazotrophs vs. PADs associated with large particles.

We also found that Trichodesmium accounted for the majority $(87 \%)$ of the nitrogenase mRNA transcripts of PADs (Fig. 4). However, an analysis of the nifH RNA/ DNA ratio showed that the nifH gene expression level of Trichodesmium was lower than that of rare but active groups (e.g., heterocystous cyanobacteria) (Fig. 6). In a previous isotope-based investigation, more than half of the Trichodesmium cells were incapable of fixing nitrogen [11]. Therefore, changes in the abundance of diazotrophic groups, determined using nifH DNA sequences, may not reflect changes in the nitrogen fixation activity of the respective members, whose ability to fix nitrogen varies. However, newly developed isotope techniques, especially NanoSIMS, allow the nitrogen fixation rate of specific groups to be investigated at the single cell level $[11,51]$.

\section{Conclusions}

In this study, the total and active communities of PADs in the northern South China Sea were inventoried, and the nifH gene expression level by different PADs groups were estimated. Active communities of PADs were significantly more divergent than the total communities.
Overall, however, the PADs communities were taxonomically diverse, with different phylogenetic groups differing in their nifH mRNA transcription activity. Despite the low abundance of heterocystous cyanobacteria, unicellular cyanobacteria, Deltaproteobacteria, and Gammaproteobacteria, the nifH transcriptional activity of these groups was high, whereas Trichodesmiumwas highly abundant but its transcriptional activity was moderate, and Betaproteobacteria and diazotrophs of cluster III were of high abundance but of low nifH transcriptional activity. Our results extend those of previous studies by specifically characterizing the distribution, abundance, and transcriptional activity of PADs in the northern South China Sea.

Nonetheless, much remains to be learned about the diversity and structure of PADs communities, including the symbiotic relationships between the various species of PADs and their hosts. Determinations of the amount of nitrogen fixation contributed by each PADs group and its impact on both host metabolism and the functioning of marine ecosystems are needed as well. Manual sorting of plankton prior to amplification and sequencing is a feasible way to assess the specificity of the symbiotic relationships between PADs and host plankton species $[25,26]$. The sequence information obtained in our study will aid in designing nucleotide probes for the in-situ visualization of specific diazotrophs in their plankton hosts. Furthermore, our findings highlight the importance of low-abundance PADs community members in understanding nitrogen fixation in marine ecosystems, but also the need for more detailed insights into the symbiotic strategies and contribution to nitrogen fixation of diazotrophic communities.

\section{Methods}

\section{Study sites and sample collection}

Seawater used for this study was collected on $R / V$ Shiyan3 cruise WPOS (20 October-10 November 2014) to the northern South China Sea. Plankton samples were obtained at nine sites using a vertical haul with a 100$\mu \mathrm{m}$-mesh, 0.4-m-diameter plankton net (Fig. 7; see Additional file 1: Table S1 for more information on the sampling locations). The samples were rinsed with 0.22 $\mu \mathrm{m}$-filtered seawater and the final volume was adjusted to $1 \mathrm{~L}$. The collected samples were thoroughly mixed and a $250-\mathrm{ml}$ aliquot was fixed with $0.1 \%$ Lugol's iodine solution for Trichodesmium counting by microscopy [52]. The remaining volume of each sample was incubated in DNA/RNA Sample Protector Buffer (Takara BioInc. Japan), and stored at $-20^{\circ} \mathrm{C}$ until nucleic acid extraction. Additionally, seawater samples were collected using a CTD system (Sea-Bird Scientific Inc. WA, USA) fitted with temperature, conductivity, $\mathrm{pH}$ and dissolved oxygen probes. The seawater was filtered through a 


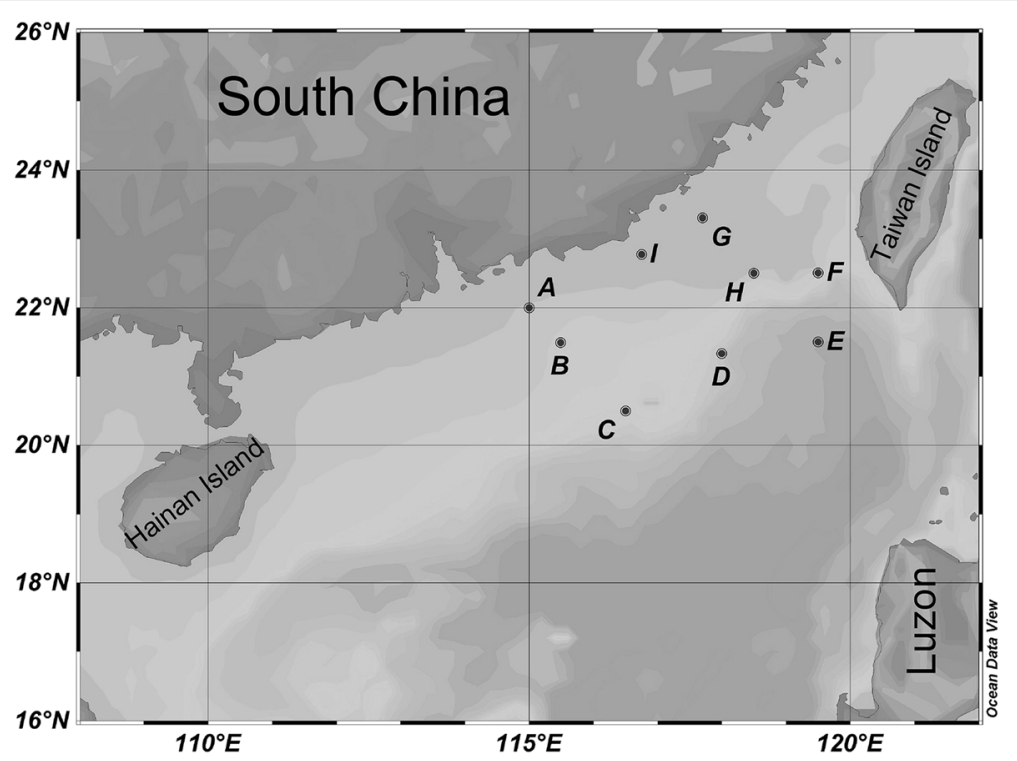

Fig. 7 Location of the sampling stations. The map was generated using ODV software (Schlitzer, R., Ocean Data View, http://odv.awi.de, 2015)

0.22- $\mu \mathrm{m}$ PEGF membrane (Millipore, Darmstadt, Germany) and then stored at $-20^{\circ} \mathrm{C}$ for nutrient concentration measurements [53].

\section{Nucleic acid extraction, cDNA synthesis and Illunima sequencing}

By centrifuging at $5000 \times \mathrm{g}$ for $5 \mathrm{~min}$, the supernatant of DNA/RNA protector buffer was removed from each sample prior to nucleic acid extraction. DNA and RNA were simultaneously extracted using a total DNA/RNA isolation kit (Omega Bio-tek, Inc. GA, USA) and their concentrations were measured using a NanoDrop 2000 spectrophotometer (Thermo Fisher Scientific Inc. DE, USA). Genomic DNA was removed from the RNA extracts by DNase digestion (Takara BioInc. Japan) prior to cDNA synthesis using a PrimeScript RT reagent kit (Takara BioInc. Japan). The 20- $\mu$ l reverse transcription reaction contained $2 \mu \mathrm{l}(<2 \mu \mathrm{g})$ of RNA. A negative control without reverse transcriptase was included to check for genomic DNA contamination of the cDNA.

The nifH gene of the DNA and cDNA were amplified using the primer pair PolF and PolR [54] combined with barcode sequences. Amplification was performed in reaction mixtures consisted of $25 \mu \mathrm{l}$ Ex Taq $(2 \times)$ (Takara BioInc. Japan), $1 \mu \mathrm{l}$ of primer PolF $(10 \mu \mathrm{M}), 1 \mu \mathrm{l}$ of primer PolR $(10 \mu \mathrm{M})$ and $1 \mu \mathrm{l}$ of DNA/cDNA in a $50-\mu \mathrm{l}$ final volume. The thermal profile was as follows: initial denaturation at $94^{\circ} \mathrm{C}$ for $5 \mathrm{~min}$, followed by 35 cycles of denaturation at $94{ }^{\circ} \mathrm{C}$ for $30 \mathrm{~s}$, annealing at $54{ }^{\circ} \mathrm{C}$ for $45 \mathrm{~s}$ and extension at $72{ }^{\circ} \mathrm{C}$ for $45 \mathrm{~s}$, and final elongation at $72{ }^{\circ} \mathrm{C}$ for $10 \mathrm{~min}$. Libraries were constructed from the purified PCR products of each sample. The $2 \times 250$-bp paired-ends sequencing was conducted on a HiSeq 2500 platform, Illumina (Genewiz, Suzhou, China).

\section{Phylogenetic analysis}

Quality trimming was done using Btrim with a quality score threshold to 20 [55]. Forward and reverse reads were merged using FLASH [56]; the overlaps of the merged reads more than $30 \mathrm{bp}$ and mismatch less than $5 \%$ were kept, otherwise filtered out. Sequences with a length $<300$ base pairs and ambiguous bases $>0$ were removed. The forward and reverse primers were trimmed before further analysis. Operational taxonomic units (OTUs) were classified using UCLUST, based on 94\% sequence similarity, as described previously [57]. Chimeric OTUs were removed using UCHIME in de novo mode [58]. Frame-shift errors in the sequences were checked and corrected using RDP FrameBot [59]. All libraries were subsampled with 100 iterations to 4746 sequence reads (smallest library size) to standardize uneven sequencing depths, resulting in a normalized OTUs table.

The validated nifH sequences were translated into amino acid sequences for phylogenetic analysis. Among the OTUs in the nifH DNA and RNA libraries, whose normalized reads in all samples were aggregated, the 20 most abundant OTUs across samples were assigned by ranking the aggregated reads. Representative sequences of the 20 most abundant OTUs (accounting for $90.3 \%$ of the total sequences) were checked against the closest related sequences in the GenBank database and in an ARB nifH database [60]. We selected the reference sequences based on the nucleotide sequence similarity and the score obtained from the BLAST: 1) sequences from the 
top 3-5 matching hits and 2) one sequence derived from pure culture isolates that scored highest. Based on these criteria, a total of 39 sequences were retrieved, where 26 sequences were derived from environmental clones, and the other 13 sequences from pure culture isolates. The nifH protein sequences of the 20 most abundant OTUs and 39 reference sequences were used to construct the phylogenetic tree. A neighbor-joining phylogenetic tree was constructed using MEGA software (v6.02) [61]. Bootstrap confidence values of the nodes were obtained by 1000 iterations. Substitution model of Poisson, uniform rates among sites and homogeneous pattern among lineages were used for MEGA. The taxonomic affiliation of the 20 abundant OTUs was assigned based on their phylogenetic relatedness to the reference sequences on the tree. Representative nifH gene sequences were deposited in the GenBank database under accession numbers KY774953-KY774972.

\section{Quantification of nifH mRNA expression level}

The primers PolF and PolR [54] were used to quantify the ratio of nifH mRNA/nifH DNA. The amplification was performed in 20- $\mu$ l reaction mixtures containing $10 \mu \mathrm{l}$ of SYBR Premix Ex TaqII $(2 \times)$ (Takara BioInc. Japan), $0.8 \mu \mathrm{l}$ of primer PolF $(10 \mu \mathrm{M}), 0.8 \mu \mathrm{l}$ of primer PolR $(10 \mu \mathrm{M})$ and $1 \mu \mathrm{l}$ of DNA/cDNA sample. Quantitative PCR was carried out using the Light Cycler 480 System (Roche Molecular Systems, Inc. CA, USA) and the following PCR conditions: $2 \mathrm{~min}$ at $95^{\circ} \mathrm{C}, 45$ cycles of $94{ }^{\circ} \mathrm{C}$ for $30 \mathrm{~s}, 54{ }^{\circ} \mathrm{C}$ for $45 \mathrm{~s}$, and $72{ }^{\circ} \mathrm{C}$ for $45 \mathrm{~s}$. All reactions were performed in triplicate. The specificity of the amplification was confirmed by melting-curve analysis and electrophoresis in a $2 \%$ agarose gel.

The ratio of nifH mRNA and nifH DNA in the bulk communities was calculated according to Eq. 1:

$$
R_{b u l k}=E^{\Delta C t}
$$

where $R$ is the resulting ratio of nifH mRNA/nifH DNA, $E$ is the amplification efficiency, and $\Delta C t$ the cycle threshold difference between nifH mRNA and nifH DNA. The amplification efficiency was calculated using established standards, as described in [62]. The nifH RNA/DNA ratio of the main PADs groups was further calculated by multiplying the nifH RNA/DNA ratio obtained from the bulk community by the respective frequencies of the dominant groups (Eq. 2):

$$
R_{\text {group }}=R_{\text {bulk }}\left(f_{\mathrm{RNA}} / f_{\mathrm{DNA}}\right)
$$

where $f$ is the frequency of each group in either the RNA or the DNA library.

\section{Statistical analysis}

Diversity indexes were calculated based on 100 resampled OTUs tables. The Chao1 index, Shannon index $(\mathrm{H})$, Simpson index (D), and Pielou evenness (J) were calculated to determine the alpha-diversity of the nifH-derived communities. Student's t-test was used to identify the significance of the difference in the diversity indexes between the RNA and DNA libraries. A Monte Carlo permutation test was performed to evaluate the correlation between environmental attributes and nifH sequences. Differences in community composition among the nine sampling stations and between the total and active PADs communities were identified using non-metric multidimensional scaling (NMDS) with a Bray-Curtis dissimilarity distance. An analysis of betadispersion [63] was used to quantify between-community variations in the total and the active PADs communities, and a redundancy analysis (RDA) to explore the relationship between diazotrophic groups and environmental parameters. Statistical analyses in this study were performed using the $\mathrm{R}$ vegan package (v3.5.1) and an R-based pipeline, as previously described [62].

\section{Additional file}

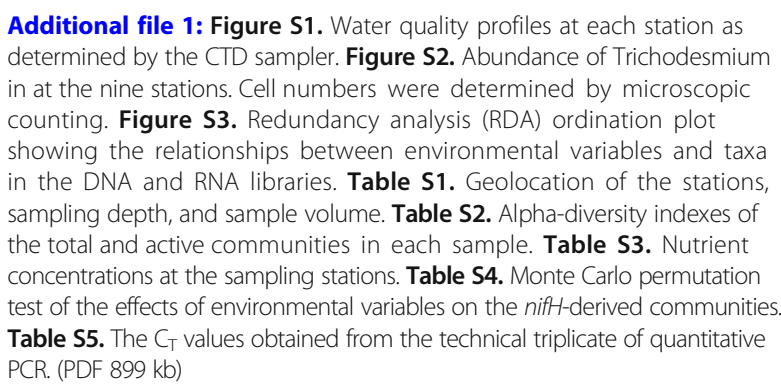

Additional file 1: Figure S1. Water quality profiles at each station as determined by the CTD sampler. Figure S2. Abundance of Trichodesmium in at the nine stations. Cell numbers were determined by microscopic counting. Figure S3. Redundancy analysis (RDA) ordination plot showing the relationships between environmental variables and taxa in the DNA and RNA libraries. Table S1. Geolocation of the stations, sampling depth, and sample volume. Table S2. Alpha-diversity indexes of the total and active communities in each sample. Table S3. Nutrient concentrations at the sampling stations. Table S4. Monte Carlo permutation test of the effects of environmental variables on the nifH-derived communities. Table S5. The $C_{T}$ values obtained from the technical triplicate of quantitative PCR. (PDF 899 kb)

\section{Acknowledgments}

We thank Dr. Jiexin Xu for CTD data processing, and all members of the RN Shiyan3 for their work on the cruises. We thank two anonymous reviewers for their constructive comments on the earlier version of the manuscript.

\section{Authors' contributions}

YYZ, JDD, YHT and QSY conceived the research. QSY, WGZ, YZZ and JL collected sample and performed the experiments. QSY and DDS performed data analysis. DDS, MA and QSY wrote the manuscript. QSY and DDS edited the manuscript. All authors approved the manuscript.

\section{Funding}

This research was supported by the Strategic Priority Research Program of the Chinese Academy of Sciences (XDA13020300 and XDA11020202), the National Natural Science Foundation of China (41676107, 41276114, and 41676163), and the Science and Technology Planning Project of Guangdong Province, China (2017B030314052). The postdoctoral fellowship of DDS was funded by the Leibniz Institute for Baltic Sea Research (IOW) in Germany.

\section{Availability of data and materials}

The datasets used and/or analyzed for the present study are available from the corresponding author on reasonable request. The nucleotide sequences have been deposited in GenBank nucleotide database of NCBI under accession numbers (KY774953-KY774972). 


\section{Ethics approval and consent to participate}

Not applicable.

\section{Consent for publication}

Not applicable.

\section{Competing interests}

The authors declare that they have no competing interests.

\section{Author details}

${ }^{1}$ CAS Key Laboratory of Tropical Marine Bio-resources and Ecology, Guangdong Provincial Key Laboratory of Applied Marine Biology, South China Sea Institute of Oceanology, Chinese Academy of Sciences, Guangzhou 510301, China. ${ }^{2}$ Tropical Marine Biological Research Station in Hainan, South China Sea Institute of Oceanology, Chinese Academy of Sciences, Sanya 572000, China. ${ }^{3}$ University of Chinese Academy of Sciences, Beijing 100049, China. ${ }^{4}$ State Oceanic Administration Sansha Marine Environmental Monitoring Center Station, Haikou 570311, China. ${ }^{5}$ Section of Biological Oceanography, Leibniz Institute for Baltic Sea Research, 18119 Warnemünde, Germany.

Received: 18 April 2019 Accepted: 5 August 2019

Published online: 15 August 2019

\section{References}

1. Zehr JP, Kudela RM. Nitrogen cycle of the open ocean: from genes to ecosystems. Annu Rev Mar Sci. 2011;3:197-225.

2. Zehr JP, Ward BB. Nitrogen cycling in the ocean: new perspectives on processes and paradigms. Appl Environ Microb. 2002;68(3):1015-24.

3. Karl DM, Letelier RM. Nitrogen fixation-enhanced carbon sequestration in low nitrate, low chlorophyll seascapes. Mar Ecol Prog Ser. 2008;364:257-68.

4. Karl DM, Church MJ, Dore JE, Letelier RM, Mahaffey C. Predictable and efficient carbon sequestration in the North Pacific Ocean supported by symbiotic nitrogen fixation. P Natl Acad Sci USA. 2012;109(6):1842-9.

5. Zehr JP. Nitrogen fixation by marine cyanobacteria. Trends Microbiol. 2011; 19(4):162-73.

6. Capone DG, Zehr JP, Paerl HW, Bergman B, Carpenter EJ. Trichodesmium, a globally significant marine cyanobacterium. Science. 1997;276(5316):1221-9.

7. Carpenter EJ, Romans K. Major role of the cyanobacterium Trichodesmium in nutrient cycling in the North-Atlantic Ocean. Science. 1991;254(5036):1356-8.

8. Carpenter EJ, Price CC. Marine oscillatoria (Trichodesmium) - explanation for aerobic nitrogen-fixation without heterocysts. Science. 1976;191(4233):1278-80.

9. Carpenter EJ, Montoya JP, Burns J, Mulholland MR, Subramaniam A, et al. Extensive bloom of a N-2-fixing diatom/cyanobacterial association in the tropical Atlantic Ocean. Mar Ecol Prog Ser. 1999;185:273-83.

10. Villareal TA, Brown CG, Brzezinski MA, Krause JW, Wilson C. Summer diatom blooms in the north pacific subtropical gyre: 2008-2009. PLoS One. 2012; 7(4):15.

11. Martinez-Perez C, Mohr W, Loescher CR, Dekaezemacker J, Littmann S, et al. The small unicellular diazotrophic symbiont, UCYN-A, is a key player in the marine nitrogen cycle. Nat Microbiol. 2016;1(11):16163.

12. Zehr JP, Jenkins BD, Short SM, Steward GF. Nitrogenase gene diversity and microbial community structure: a cross-system comparison. Environ Microbiol. 2003;5(7):539-54.

13. Zehr JP, Mellon MT, Zani S. New nitrogen-fixing microorganisms detected in oligotrophic oceans by amplification of Nitrogenase ( $\mathrm{nifH}$ ) genes. Appl Environ Microb. 1998:64(9):3444-50.

14. Bonnet S, Biegala IC, Dutrieux P, Slemons LO, Capone DG. Nitrogen fixation in the western equatorial Pacific: rates, diazotrophic cyanobacterial size class distribution, and biogeochemical significance. Global Biogeochem Cy. 2009; 23(3):1874-92

15. Foster RA, Kuypers MM, Vagner T, Paerl RW, Musat N, et al. Nitrogen fixation and transfer in open ocean diatom-cyanobacterial symbioses. ISME J. 2011; 5(9):1484-93.

16. Mague TH, Weare NM, Holmhans $\mathrm{O}$. Nitrogen-fixation in north pacific ocean. Mar Biol. 1974:24(2):109-19.

17. Gomez F, Furuya K, Takeda S. Distribution of the cyanobacterium Richelia intracellularis as an epiphyte of the diatom Chaetoceros compressus in the western Pacific Ocean. J Plankton Res. 2005;27(4):323-30.
18. Momper LM, Reese BK, Carvalho G, Lee P, Webb EA. A novel cohabitation between two diazotrophic cyanobacteria in the oligotrophic ocean. ISME J. 2015:9(4):882-93.

19. Frischkorn KR, Rouco M, Van Mooy BAS, Dyhrman ST. Epibionts dominate metabolic functional potential of Trichodesmium colonies from the oligotrophic ocean. ISME J. 2017;11(9):2090-101.

20. Venrick EL. Distribution and significance of richelia-intracellularis schmidt in north pacific central gyre. Limnol Oceanogr. 1974;19(3):437-45.

21. Rai AN, Soderback E, Bergman B. Cyanobacterium-plant symbioses. New Phytol. 2000;147(3):449-81.

22. Bothe H, Tripp HJ, Zehr JP. Unicellular cyanobacteria with a new mode of life: the lack of photosynthetic oxygen evolution allows nitrogen fixation to proceed. Arch Microbiol. 2010;192(10):783-90.

23. Proctor LM. Nitrogen-fixing, photosynthetic, anaerobic bacteria associated with pelagic copepods. Aquat Microb Ecol. 1997:12(2):105-13.

24. Braun ST, Proctor LM, Zani S, Mellon MT, Zehr JP. Molecular evidence for zooplankton-associated nitrogen-fixing anaerobes based on amplification of the nifH gene. FEMS Microbiol Ecol. 1999;28(3):273-9.

25. Azimuddin KM, Hirai J, Suzuki S, Haider MN, Tachibana A, et al. Possible association of diazotrophs with marine zooplankton in the Pacific Ocean. MicrobiologyOpen. 2016;5(6):1016-26.

26. Scavotto RE, Dziallas C, Bentzon-Tilia M, Riemann L, Moisander PH. Nitrogenfixing bacteria associated with copepods in coastal waters of the North Atlantic Ocean. Environ Microbiol. 2015;17(10):3754-65.

27. Farnelid H, Turk-Kubo K, Ploug H, Ossolinski JE, Collins JR, et al. Diverse diazotrophs are present on sinking particles in the North Pacific Subtropical Gyre. ISME J. 2019;13:170-82.

28. Jones SE, Lennon JT. Dormancy contributes to the maintenance of microbial diversity. P Natl Acad Sci USA. 2010;107(13):5881-6.

29. Lennon JT, Jones SE. Microbial seed banks: the ecological and evolutionary implications of dormancy. Nat Rev Microbiol. 2011;9(2):119-30.

30. Zehr JP, Turner PJ. Nitrogen fixation: Nitrogenase genes and gene expression. Method Microbiol. 2001;30:271-86.

31. Zhang Y, Zhao Z, Dai M, Jiao N, Herndl GJ. Drivers shaping the diversity and biogeography of total and active bacterial communities in the South China Sea. Mol Ecol. 2014;23(9):2260-74.

32. Wilhelm $L$, Besemer $K$, Fasching $C$, Urich $T$, Singer GA, et al. Rare but active taxa contribute to community dynamics of benthic biofilms in glacier-fed streams. Environ Microbiol. 2014;16(8):2514-24.

33. Klein AM, Bohannan BJ, Jaffe DA, Levin DA, Green JL. Molecular evidence for metabolically active bacteria in the atmosphere. Front Microbiol. 2016;7:772.

34. Zhang Y, Zhao Z, Sun J, Jiao N. Diversity and distribution of diazotrophic communities in the South China Sea deep basin with mesoscale cyclonic eddy perturbations. FEMS Microbiol Ecol. 2011;78(3):417-27.

35. Kong L, Jing H, Kataoka T, Sun J, Liu H. Phylogenetic diversity and spatiotemporal distribution of nitrogenase genes (nifH) in the northern South China Sea. Aquat Microb Ecol. 2011;65(1):15-27.

36. Romanowicz KJ, Freedman ZB, Upchurch RA, Argiroff WA, Zak DR. Active microorganisms in forest soils differ from the total community yet are shaped by the same environmental factors: the influence of $\mathrm{pH}$ and soil moisture. FEMS Microbiol Ecol. 2016;92(10).

37. Freedman ZB, Romanowicz KJ, Upchurch RA, Zak DR. Differential responses of total and active soil microbial communities to long-term experimental $\mathrm{N}$ deposition. Soil Biol Biochem. 2015;90:275-82.

38. Hunt DE, Lin Y, Church MJ, Karl DM, Tringe SG, et al. Relationship between abundance and specific activity of bacterioplankton in open ocean surface waters. Appl Environ Microb. 2012;79(1):177-84.

39. Wang J, Bao JT, Li XR, Liu YB. Molecular ecology of nifH genes and transcripts along a chronosequence in revegetated areas of the tengger desert. Microb Ecol. 2016:71(1):150-63.

40. Short SM, Zehr JP. Quantitative analysis of nifH genes and transcripts from aquatic environments. In: Environmental microbiology Edited by Leadbetter JR, vol. 397; 2005: 380-394.

41. Church MJ, Short CM, Jenkins BD, Karl DM, Zehr JP. Temporal patterns of nitrogenase gene ( $\mathrm{nifH}$ ) expression in the oligotrophic North Pacific Ocean. Appl Environ Microb. 2005;71(9):5362-70.

42. De Vrieze J, Regueiro L, Props R, Vilchez-Vargas $R$, Jauregui $R$, et al. Presence does not imply activity: DNA and RNA patterns differ in response to salt perturbation in anaerobic digestion. Biotechnol Biofuels. 2016;9:244 
43. Shade A, Jones SE, Caporaso JG, Handelsman J, Knight R, et al. Conditionally rare taxa disproportionately contribute to temporal changes in microbial diversity. mBio. 2014;5(4):e01371-14.

44. Biegala IC, Raimbault P. High abundance of diazotrophic picocyanobacteria $(<3 \mu \mathrm{m})$ in a Southwest Pacific coral lagoon. Aquat Microb Ecol. 2008;51:45-53.

45. Moisander PH, Serros T, Paerl RW, Beinart RA, Zehr JP. Gammaproteobacterial diazotrophs and nifH gene expression in surface waters of the South Pacific Ocean. ISME J. 2014;8(10):1962-73.

46. Mazard SL, Fuller NJ, Orcutt KM, Bridle O, Scanlan DJ. PCR analysis of the distribution of unicellular cyanobacterial diazotrophs in the Arabian Sea. Appl Environ Microb. 2004;70(12):7355-64

47. Mehta MP, Huber JA, Baross JA. Incidence of novel and potentially archaeal nitrogenase genes in the deep Northeast Pacific Ocean. Environ Microbiol. 2005;7(10):1525-34.

48. Lilburn TC, Kim KS, Ostrom NE, Byzek KR, Leadbetter JR, et al. Nitrogen fixation by symbiotic and free-living spirochetes. Science. 2001;292(5526): 2495-8.

49. Wu J, Chung SW, Wen LS, Liu KK, Chen YL, et al. Dissolved inorganic phosphorus, dissolved iron, and Trichodesmiumin the oligotrophic South China Sea. Global Biogeochem Cy. 2003;17(1):1-10.

50. Villareal TA. Abundance and photosynthetic characteristics of Trichodesmium spp. along the Atlantic barrier reef at carrie bow cay, Belize. Mar Ecol. 1995; 16(3):259-71.

51. Behrens S, Losekann T, Pett-Ridge J, Weber PK, Ng WO, et al. Linking microbial phylogeny to metabolic activity at the single-cell level by using enhanced element labeling-catalyzed reporter deposition fluorescence in situ hybridization (EL-FISH) and NanoSIMS. Appl Environ Microb. 2008;74(10): 3143-50.

52. Guillou L, Nezan E, Cueff V, Erard-Le Denn E, Cambon-Bonavita MA, et al. Genetic diversity and molecular detection of three toxic dinoflagellate genera (Alexandrium, Dinophysis, and Karenia) from French coasts. Protist. 2002;153(3):223-38.

53. Huang $L$, Tan $Y$, Song $X$, Huang $X$, Wang $H$, et al. The status of the ecological environment and a proposed protection strategy in Sanya Bay, Hainan Island. China Mar Pollut Bull. 2003;47(1-6):180-6.

54. Poly F, Monrozier LJ, Bally R. Improvement in the RFLP procedure for studying the diversity of nifH genes in communities of nitrogen fixers in soil. Res Microbiol. 2001;152(1):95-103.

55. Kong Y. Btrim: a fast, lightweight adapter and quality trimming program for next-generation sequencing technologies. Genomics. 2011;98(2):152-3.

56. Magoc T, Salzberg SL. FLASH: fast length adjustment of short reads to improve genome assemblies. Bioinformatics. 2011;27(21):2957-63.

57. Tu Q, Deng Y, Yan Q, Shen L, Lin L, et al. Biogeographic patterns of soil diazotrophic communities across six forests in the North America. Mol Ecol. 2016;25(12):2937-48

58. Edgar RC, Haas BJ, Clemente JC, Quince C, Knight R. UCHIME improves sensitivity and speed of chimera detection. Bioinformatics. 2011;27(16): 2194-200

59. Wang Q, Quensen JF, Fish JA, Lee TK, Sun Y, et al. Ecological patterns of nifH genes in four terrestrial climatic zones explored with targeted metagenomics using FrameBot, a new informatics tool. mBio. 2013;4(5): e00592-13.

60. Heller P, Tripp HJ, Turk-Kubo K, Zehr JP. ARBitrator: a software pipeline for on-demand retrieval of auto-curated nifH sequences from GenBank. Bioinformatics. 2014;30(20):2883-90.

61. Tamura K, Stecher G, Peterson D, Filipski A, Kumar S. MEGA6: molecular evolutionary genetics analysis version 6.0. Mol Biol Evol. 2013;30(12):2725-9.

62. Zhang $Y$, Yang Q, Ling J, Van Nostrand JD, Shi Z, et al. The shifts of diazotrophic communities in spring and summer associated with coral galaxea astreata, pavona decussata, and porites lutea. Front Microbiol. 2016:7:1870.

63. Anderson MJ. Distance-based tests for homogeneity of multivariate dispersions. Biometrics. 2006;62(1):245-53.

\section{Publisher's Note}

Springer Nature remains neutral with regard to jurisdictional claims in published maps and institutional affiliations.

\section{Ready to submit your research? Choose BMC and benefit from:}

- fast, convenient online submission

- thorough peer review by experienced researchers in your field

- rapid publication on acceptance

- support for research data, including large and complex data types

- gold Open Access which fosters wider collaboration and increased citations

- maximum visibility for your research: over $100 \mathrm{M}$ website views per year

At BMC, research is always in progress.

Learn more biomedcentral.com/submissions 